Working Paper

Business Economic Series

WP. 12-02

ISSN 1989-8843
Instituto sobre Desarrollo Empresarial

Carmen Vidal Ballester. Universidad Carlos III de Madrid

C/ Madrid, 126

28903 Getafe Madrid (Spain)

FAX (34-91)6249607

\title{
The Role of Connections in Academic Promotions
}

\author{
Natalia Zinovyeva \\ Institute of Public Goods and Policies (IPP-CSIC) \\ natalia.zinovyeva@csic.es \\ Manuel Bagues \\ Universidad Carlos III de Madrid \\ mfbagues@emp.uc3m.es
}




\title{
The Role of Connections in Academic Promotions*
}

\author{
Natalia Zinovyeva ${ }^{\dagger} \quad$ Manuel Bagues $\ddagger$
}

September 7, 2012

\begin{abstract}
This paper analyzes the role of connections in academic promotions. We exploit evidence from centralized evaluations in Spain, where evaluators are randomly assigned to promotion committees. We find that prior connections between candidates and evaluators have a dramatic impact on candidates' success. For instance, the presence of a co-author or an advisor in the committee is equivalent to a standard deviation increase in candidates' research output. The effect of a weaker link, such as a member of candidate's doctoral thesis committee, is one fourth as large. The source of the premium enjoyed by connected candidates depends on the nature of their relationship with committee members. In the case of weak links, informational gains tend to dominate evaluation biases. Candidates promoted by a weak link turn out to be more productive in the future relative to other promoted candidates. However, consistently with the potential existence of favoritism, candidates promoted by a strong connection exhibit a significantly worse research record both before and after the evaluation.
\end{abstract}

Keywords: academic promotion, connections, evaluation bias, information asymmetries

JEL Classification: J44, M51

*An earlier version of this paper was circulated under the title "It's Not What You Know, but Who You Know? The Role of Connections in Academic Promotions." We are extremely grateful to Berta Esteve-Volart, Dan Hamermesh, Eduardo Melero, Nic Morgan, Heidi Williams and participants at presentations at the DIME-BRICK workshop, Simposio de Análisis Económico, European Society of Population Economics, Università Bocconi, Universidad Carlos III, NBER Summer Institute and the European Economic Association for their valuable comments. Both authors acknowledge the support from the Spanish Ministry of Science and Innovation (grant CSO2011-29431 and Ramón y Cajal program).

${ }^{\dagger}$ Institute of Public Goods and Policies (IPP-CSIC). Email: natalia.zinovyeva@csic.es

${ }_{\ddagger}^{\ddagger}$ Universidad Carlos III de Madrid. Email: mfbagues@emp.uc3m.es 


\section{Introduction}

Science is largely relying on a non-market reward system, based on meritocracy and credit granted by peers (Stephan 1996). Failures in this system might have important consequences for the overall quality of research. A potential threat is the existence of previous connections between candidates and evaluators. Evaluators may favor connected candidates out of nepotism or because they share a common view on which academic areas are more valuable. ${ }^{1}$ However, the presence of acquainted evaluators might also improve the efficiency of a selection process, as they might be better informed about candidates' quality.

The net effect of this trade-off, the potential existence of an evaluation bias versus the positive informational effect of connections, may vary depending on the nature of connections and the institutional setup. The empirical evidence is relatively scarce. ${ }^{2}$ Laband and Piette (1994) and Brogaard et al. (2012) show that, in top Economics journals, editors take advantage of their connections with colleagues from their own institution in order to identify and 'capture' high-impact papers for publication. Li (2011) finds that the presence of related reviewers, as measured by citations, improves the quality of research supported by the National Institute of Health (NIH). Whether these results hold in other contexts or whether they apply to other types of connections remains an open question.

In this paper we study the role of connections in academic promotions using the exceptional evidence provided by the system of centralized evaluations that was in place in Spain from 2002 through 2006. During this period, candidates both to full professor and associate professor positions were evaluated by a committee at the national level. ${ }^{3}$

\footnotetext{
${ }^{1}$ As Joseph A. Schumpeter (1954) pointed out, "it is merely human nature that we overrate the importance of our own types of research and underrate the importance of the types that appeal to others." (History of Economic Analysis, London: George Allen and Unwin, 1954, page 20.)

${ }^{2} \mathrm{~A}$ number of studies observe that connected candidates are more likely to be promoted. For instance, evidence from France and Italy shows that promotion committees tend to prefer connected candidates, conditional on their observable research production (Perotti 2002, Combes et al. 2008, De Paola and Scoppa 2011, Durante et al. 2011). This evidence is consistent both with the existence of informational asymmetries and an evaluation bias.

${ }^{3}$ The position of catedrático de universidad at a Spanish university may be considered equivalent to the position of full professor in a U.S. university. The category of profesor titular de universidad would be equivalent to associate professor; in Spain, the position of associate professor typically carries tenure.
} 
Successful candidates could then apply for a position at the university level. ${ }^{4}$ The evidence provided by centralized competitions has several convenient features for the analysis. First, committee members were selected out of the pool of eligible professors in the discipline using a random lottery. Our empirical strategy exploits this random assignment of evaluators to committees. This approach allows for the possibility that connected candidates are better in dimensions that are observable to evaluators but not to the econometrician. Second, conflict of interest rules were seldom implemented. As a result, it is possible to study the effect of different types of connections between evaluators and candidates, including very close ones such as thesis advisors, co-authors and colleagues as well as weaker ties. Finally, the system affected a large number of researchers at every academic discipline. In total, our database includes information on thirty thousand candidacies evaluated by approximately one thousand committees. The size and the breadth of the database allow us to investigate the robustness of results along a number of dimensions.

Connections have a significant positive impact on candidates' chances of being promoted. The magnitude of the effect is increasing with the strength of the connection. Candidates have $78 \%$ more chances of being promoted if the committee includes, by luck of the draw, a strong connection such as their doctoral thesis advisor or a co-author; the presence in the committee of a colleague from the same university increases candidates' chances of success by $35 \%$, and the presence of a weak connection, such as a professor with whom the candidate had interacted previously at some $\mathrm{PhD}$ thesis defense, by $19 \%$. The importance of connections is commensurate with the relevance of observable research quality, as measured by the number of publications in ISI Web of Science, received citations, and participation in thesis committees. For instance, the presence of a strong connection in the evaluation committee is equivalent to a one standard deviation increase in candidates' observable quality.

The information on candidates' research production during the five-year period fol-

\footnotetext{
${ }^{4}$ This procedure is relatively similar to promotion systems currently in place in other countries in continental Europe. In France, professors are recruited through a centralized examination (concours nationaux d'agrégation). In Italy, the Moratti Law (2005) introduced a nation-wide qualification exam for candidates to university positions (l'idoneità nazionale).
} 
lowing the evaluation suggests that the source of the premium enjoyed by connected candidates depends on the nature of their relationship with committee members. Information asymmetries about candidates' research quality may explain why evaluators are more likely to promote weakly connected candidates. Candidates that were promoted by a committee that included a weak tie turn out to be significantly more productive in the future relative to other promoted candidates. On the contrary, candidates who were promoted by a committee that included their thesis advisor, a co-author or a colleague exhibit a worse research record both before and after the evaluation. In this case, evaluators seem to be willing to 'sacrifice' candidates' research production in exchange for getting connected candidates promoted. There are at least two possible explanations for this behavior. Strong connections might be benefiting from cronyism. Alternatively, the larger success rate of these candidates might reflect the existence of information asymmetries in some other dimension that is only observable for strongly connected evaluators, such as candidates' willingness to help other colleagues (Oettl 2012). However, it seems unlikely that these information asymmetries can fully explain the large premium associated to connections. According to survey information, publications in journals covered by ISI Web of Science were the most important factor for promotion decisions. ${ }^{5}$ Overall, our analysis suggests that the balance between the positive informational effect of connections and the potential existence of evaluation biases varies depending on the strength of connections.

The rest of the paper is organized as follows. Section 2 describes the institutional background. Section 3 provides details on the data and the definition of variables. In section 4 we present the empirical evidence and we investigate possible explanations for the effect of connections. Finally, in section 5 we summarize our results and discuss possible policy implications.

\footnotetext{
${ }^{5}$ Survey completed by 1,294 eligible evaluators (Sierra et al. 2009).
} 


\section{Institutional background}

European countries are increasingly concerned with the efficiency of their universities. In an attempt to strengthen meritocracy, during the last decade several countries have reformed the organization of universities (Aghion et al. 2010). In this respect, Spain offers an insightful case.

Before 2002, Spanish public universities had a large degree of autonomy regarding hiring and promotion. ${ }^{6}$ This system was largely associated with inbreeding, generating public concerns about the potential existence of favoritism. ${ }^{7}$ In order to increase meritocracy, in 2002 a system of centralized competitions known as habilitación was introduced by the government. ${ }^{8}$ The new system involved two stages. First, candidates to full and associate professor positions were required to qualify in a national competition held at the discipline level. ${ }^{9}$ Successful candidates could then apply for a position at a given university. The number of positions created at the national level was very limited, and competition at the university level was largely absent. Thus, in practice, being accredited was generally equivalent to being promoted. Notably, committee members in centralized competitions were selected by random draw from the pool of all evaluators in the field. In 2006, the system of habilitación was replaced by a system known as acreditación, which is still in place. As in the system of habilitación, applicants are required to be accredited by a national review committee. However, under the new system, committee members are selected from the pool of professors who volunteer for the task, and there is no limit to the number of candidates who may receive the accreditation.

In this paper we analyze centralized competitions in the Spanish public university

\footnotetext{
${ }^{6}$ As is generally the case in Europe, most university professors in Spain are based in public universities. In Spain, approximately $88 \%$ of university professors work in a public institution (Source: Instituto Nacional de Estadística 2010).

${ }^{7}$ According to Cruz-Castro et al. (2006) in the nineties $93 \%$ of university tenured positions were assigned to internal candidates. Approximately $70 \%$ of these candidates had also done their $\mathrm{PhD}$ in the same university.

${ }^{8}$ This motivation for the reform was expressed, among others, by Julio Iglesias de Ussel, vice-minister for Education and Universities (newspaper El País, November 5th, 2001). Detailed information about this system of centralized competitions is available at the State Bulletin (http://www.boe.es/boe/ dias/2002/08/07/pdfs/A29254-29268.pdf)

${ }^{9}$ There are nearly two hundred legally defined academic disciplines. These disciplines were created in 1984 on the basis of "the homogeneity of its object of knowledge, a common historic tradition and the existence of a community of researchers" (R.D. 1988/84).
} 
system during 2002-2006. The time structure of examinations was as follows. First, universities reported the number of openings to the Ministry. ${ }^{10}$ The centralized competition was then announced, and candidates were allowed to apply within twenty days. Once the list of applicants was settled, committee members were selected by random draw from the list of eligible evaluators. This list included those professors and researchers who were working in public institutions in Spain at the time, and who were officially recognized to have a minimum research quality in the discipline. ${ }^{11}$ Around $80 \%$ of full professors and approximately $70 \%$ of associate professors qualified. ${ }^{12}$ The selection was carried out by Ministry officials using a drum which contained as many balls as there were eligible evaluators.

Each committee was composed of seven members. In exams to associate professor positions, three evaluators were chosen from the list of eligible full professors (henceforth FP), and four evaluators were chosen from the list of eligible associate professors (henceforth $\mathrm{AP}$ ). In the case of exams to FP positions, all committee members were chosen from the list of eligible FPs. The committee member with the longest tenure was appointed president, and the exam was held at the university where the president was based.

Further, seven evaluators were randomly assigned to form a committee in reserve. Their role was to replace evaluators in case somebody resigned from the committee. Evaluators could only resign under a very restricted set of reasons, and resignations happened very rarely: about $2 \%$ of initially assigned evaluators were replaced. There are

\footnotetext{
${ }^{10}$ Even though the number of available accreditations was equal to the total number of openings requested by universities, these accreditations were not directly linked to university openings. Universities that had requested a position were not forced to hire one of the candidates who were accredited in the following competition. Universities could postpone hiring decisions, or they could hire a candidate who had been accredited in the past. In fact, universities would often create a position once a local candidate had been accredited.

${ }^{11}$ The random assignment of evaluators to committees was subject to some minor constraints. Not more than one non-university researcher belonging to the Spanish Research Council (CSIC) was allowed to be selected as a member of the evaluation committee for a given exam. Similarly, not more than one emeritus professor was allowed to be selected as a member of a given evaluation committee. Therefore, in exams where the population of potential evaluators contained two or more researchers, or two or more emeritus professors, the expected committee composition should be computed taking into account this constraint. The details on these calculations are in Appendix B.

${ }^{12}$ The research quality requirement was based on the number of sexenios recognized to each professor. Sexenios are granted by the Spanish education authorities on the basis of applicants' academic research output in any non-interrupted period of a maximum of six years. Source: Comisión Nacional Evaluadora de la Actividad Investigadora, Memoria de los resultados de las evaluaciones realizadas de 1989 a 2005, 2005.
} 
two main types of resignations. Professors were allowed to decline if they were temporarily holding a high position in Spain's public administration. Also, professors were to abstain from participating in the committee if they had a very close personal connection with one of the candidates. ${ }^{13}$ With very few exceptions, evaluators did not report such connections. For instance, according to our own calculations, out of 832 professors who were assigned to evaluate their own $\mathrm{PhD}$ students, only 22 resigned from the committee, a proportion which is similar to the overall rate.

Competitions to FP positions had two qualifying stages. In the first stage each candidate presented her résumé. In the second stage candidates presented a piece of their research work. Additionally, exams to AP positions had an intermediate stage, in which candidates had to deliver a lecture on a topic from their syllabus. At each stage, passing decisions were taken on a majority basis. At the end of the process, the number of qualified candidates could not be larger than the total number of positions.

\section{Data}

We use data from three different sources. First, we have collected information on all exams to AP and FP positions that were held in Spain when the centralized system of examinations was in place (years 2002-2006). Second, we have gathered information on the research output of candidates and eligible evaluators from ISI Web of Science. Third, we use information on $\mathrm{PhD}$ dissertations read in Spain. This data allows us to identify individuals' PhD alma mater and their academic networks. In Appendix A we provide a detailed explanation on how this data was collected and how each variable was constructed. Below we describe the final database.

\footnotetext{
${ }^{13}$ The law considers three main cases: (i) the evaluator has a personal interest in the matter, (ii) there is some kinship relationship, (iii) there exists a well-known friendship (or enmity). Ley de Procedimiento Administrativo 30/1992, article 28, retrieved on February 7th 2012 at http://www. boe.es/ aeboe/consultas/bases_datos/doc.php?id=BOE-A-1992-26318. We thank Anxo Sánchez for providing us this reference.
} 


\subsection{Exams}

The dataset includes information on 967 exams, of which 465 are exams to AP positions and 502 are exams to FP positions. Table 1 provides descriptive information on the characteristics of these exams. There were on average five positions available per exam in AP exams, and three positions per exam in FP exams. The level of competition was similar; in both types of exams there were approximately ten candidates for every position. Practically all positions offered were filled.

\subsection{Evaluators}

In total, in the period we study there were 7,963 eligible FPs and 21,979 eligible APs. As shown in Table 2, the average eligible FP is 53 years old; eight years older than the average eligible AP. Women constitute $14 \%$ of eligible FPs and $35 \%$ of APs. As expected, eligible FPs tend to have a larger research record than APs. On average, FPs have nine (singleauthored equivalent) ISI publications and APs have five. ${ }^{14}$ Publications of both FP and AP professors receive around 8 citations each. Eligible FPs have supervised on average five doctoral students, while the average eligible AP has supervised only one student. Similarly, FPs have participated in almost five times more PhD thesis committees than APs, 25 and 5 respectively.

\subsection{Candidates}

During the period of study there were 13,612 applications to FP positions, and 18,138 applications to AP positions. On average, candidates applied twice, either because they failed the first time, or because they tried to simultaneously obtain a position in several related disciplines. As shown in Table 2, candidates to FP positions tend to be older, male, and to exhibit a better research record than candidates to AP positions. Applicants to FP positions have on average advised two students, and have participated in seven dissertation committees, whereas applicants to AP positions have not yet actively

\footnotetext{
${ }^{14}$ In what follows we divide publications by the number of co-authors. For instance, two publications with two co-authors are equivalent to one single-authored publication.
} 
participated in the direction of doctoral students, and only a few of them have taken part in $\mathrm{PhD}$ committees. Given that there are relatively large differences across positions and across disciplines in the propensity to publish, cite, participate in dissertations, and time necessary to progress in the career, in what follows we normalize research indicators and age to have zero mean and unit standard deviation for candidates within each exam.

In Table 3 we report the correlation between the main characteristics of candidates, pooling together information from exams to $\mathrm{FP}$ and AP positions. ${ }^{15}$ We observe that more prolific candidates tend also to have higher research quality, as measured by the number of citations received (Table 3, block B-B). Well-published candidates are also more likely to participate in students' supervision and evaluation. On average, older candidates do not have a better publication record, but they have participated more extensively in students' supervision and evaluation. There are no gender differences in terms of publications and citations, but women are significantly less likely to advise doctoral students or participate in dissertation committees.

\subsection{Links between evaluators and candidates}

We consider several types of connections between candidates and evaluators. As Granovetter (1973) points out, the strength of an interpersonal tie should be related to "the amount of time, the emotional intensity, the intimacy (mutual confiding), and the reciprocal services which characterize the tie". First, we focus on the strongest academic connections: advisors and co-authors. As shown in Table 4, approximately $13 \%$ of applicants to a FP positions happened to be evaluated by one of these strong links. In exams to AP positions, they affected $8 \%$ of candidates. Second, we investigate institutional connections. In exams to FP positions $28 \%$ of candidates had a colleague from their university (who was not an advisor or a co-author) sitting in the evaluation committee. In exams to AP positions, $25 \%$ of candidates were evaluated by a committee that included an evaluator who was based in candidates' alma mater. ${ }^{16}$ Third, we use information on

\footnotetext{
${ }^{15}$ Results are very similar if we disaggregate the table by position.

${ }^{16}$ Unfortunately we cannot observe the affiliation of candidates to AP positions at the time of the exam, we only observe the institution where they obtained their PhD. Given the low geographical mobility of Spanish professors at this stage (Cruz-Castro et al. 2006), it seems reasonable to presume that the large
} 
candidates' and evaluators' participation in $\mathrm{PhD}$ thesis committees. We consider several types of interactions: (i) the evaluator was a member of candidate's thesis committee, (ii) the evaluator has invited the candidate to sit on the thesis committee of one of her students (or vice versa) and (iii) the evaluator and the candidate participated in the same thesis committee. We denominate these links weak ties. Weak ties are relatively more frequent in exams to FP positions, where approximately $34 \%$ of candidates are evaluated by a weak link. In exams to AP positions, only $7 \%$ of candidates have a weak tie with a committee member. Finally, we define several indicators of indirect links between candidates and evaluators: the evaluator and the candidate have either (i) a common advisor, (ii) a common co-author or (iii) a common thesis committee member. To stress that these links do not necessarily imply professional interaction or awareness of each other's research, we denominate them indirect ties. These indirect ties are also relatively frequent, affecting about a fifth of candidates.

\section{Empirical analysis}

Our empirical analysis is structured as follows. First, we estimate the (causal) effect of committees' composition on applicants' chances of being promoted. In order to get a better understanding of the magnitude of the effect, we also compare the effect of connections on promotions with the effect of observable research quality. Second, we explore the effect of connections across different types of disciplines, departments, candidates and evaluators. Finally, we investigate the source of the premium associated to connections. In particular, using information on candidates' future research production, we consider the possibility that evaluators might be more accurate at assessing the research potential of candidates they are acquainted with.

majority of candidates to AP positions were still based in their alma mater at the time of the evaluation. 


\subsection{The (causal) effect of connections on promotions}

As shown in Table 4, candidates' chances of success are significantly larger when they have some connection in the evaluation committee. In exams to FP positions, candidates who are evaluated by their thesis advisor or co-author are three times more likely to be promoted than candidates who had no connections in the committee. Candidates with colleagues or weak connections among evaluators have more than twice larger chances of success relatively to unconnected candidates. Indirect connections are also associated to larger chances of success, although the premium is not as high as in the case of direct connections. The pattern is very similar in exams to AP positions.

Naturally, this descriptive evidence might be suggestive about the potential relevance of connections, but it has no causal interpretation. The larger success rate of connected candidates might simply reflect their higher quality (see Table 3, block C-B). In order to identify the causal effect of having a connection in the committee, we compare the outcomes of candidates with a similar expected committee composition but who, as a consequence of the realizations of random draws, are evaluated by committees with different composition. For instance, one may think about the case of two candidates who apply for a promotion, each one has a connection in the set of eligible evaluators, but only one of these two connected evaluators happens to be (randomly) assigned to the evaluation committee.

As pointed out in section 2, approximately $2 \%$ of evaluators drawn in the lottery where replaced. As well, according to anecdotal evidence, some professors did not attend the exam (or part of it) without a proper justification. In what follows, we measure committee composition using the outcome of the initial random draw, which might be slightly different from the committee composition that ends up evaluating candidates. Therefore, our estimates below provide the intention-to-treat effect.

The following equation describes the relationship between the candidates' probability of being promoted and the (random) number of connections in the evaluation committee:

$$
y_{i e}=\beta_{0}+\beta_{1}\left(c_{i e}-\mu_{i e}\right)+\epsilon_{i e}
$$


where $y_{i e}$ indicates whether individual $i$ qualified in exam $e$ and $\left(c_{i e}-\mu_{i e}\right)$ is the shock to committee composition, i.e., the difference between the actual $\left(c_{i e}\right)$ and the expected number of connections $\left(\mu_{i e}\right)$ of candidate $i$. Note that $\beta_{0}$ indicates the average success rate.

The key assumption in our identification strategy is that the selection of committee members was random. More formally,

$$
E\left[\left(c_{i e}-\mu_{i e}\right) \cdot \epsilon_{i e}\right]=0
$$

If this condition is satisfied, $\beta_{1}$ can be interpreted as the causal effect of an additional connection among evaluators on candidates' probability of success.

The empirical evidence is consistent with the assignment indeed being random. As shown in Table 3, there is no significant difference between the expected committee composition and the mean of the actual realization of the draw. As well, there is no relationship between the magnitude of the shocks to committee composition and candidates' characteristics (Table 3, blocks D-B and D-C).

Table 5 presents the estimation results for equation (1). Standard errors are clustered at the exam level, reflecting the fact that the shocks received by candidates in the same examination are not independent. We report results for the four aggregate sets of connections defined earlier: strong, institutional, weak and indirect connections. ${ }^{17}$ Strong connections lead to a 9 percentage points increase in applicants' likelihood of success (column 1). This is equivalent to a $78 \%$ increase relative to the average success rate (about $11 \%$ of candidates are promoted). Institutional and weak connections with committee members also have a significant positive effect. They increase candidates' chances of success by 4 and 2 percentage points respectively (approximately a $35 \%$ and a $19 \%$ increase). The effect of indirect connections is not statistically different from zero.

Weak ties are relatively more important in exams to AP positions. The importance of other connections is stable over the academic career (columns 2 and 3). Next, as a robustness check, in column 4 we control for exam fixed effects. As expected, results are

\footnotetext{
${ }^{17}$ In Appendix A we report results at a disaggregated level.
} 
unchanged. We also use an alternative identification strategy to estimate the effect of committee composition. Specifically, given that many individuals applied several times for promotion, we use a fixed-effects strategy. In other words, we compare the evaluations given to the same individual by different promotion committees. Note that this strategy is less efficient, since it does not exploit all possible variation in the data. Its internal validity is also more limited, as it considers only those individuals who participated in examinations more than once. Nevertheless, the estimates are statistically similar to the baseline estimation (column 5 vs. column 1). As an additional robustness check, we replicate the analysis for the subsample of candidates who obtained their PhD in Spain. The estimated coefficients are similar to the ones obtained for the whole sample (column 6 vs. column 1).

\subsection{The role of candidates' quality}

The results above suggest that connections have a strong effect on promotion decisions. In order to get a better understanding of the magnitude of these effects, we examine the relevance of a number of observable individual characteristics that proxy for candidates' quality. In particular, we estimate the effect of candidates' publications, the average number of citations per publication, the number of $\mathrm{PhD}$ students advised, and the number of participations in $\mathrm{PhD}$ thesis committees. We also control for age since, conditional on research output, younger candidates might have a larger potential. These variables are all normalized at the exam level.

The effect of observable research quality is commensurate with the effect of connections. Candidates who, conditional on age, score one standard deviation more than average in each one of these four observable dimensions of research quality have approximately 7 percentage points higher chances of success (Table 5, column 7). We also observe that, conditional on their research output, older candidates have lower chances of promotion.

Our analysis may be subject to a measurement error induced by homonymity. This might create an attenuation bias in our estimates for variables based on publications 
data. Given that homonymity is expected to be less of a problem for individuals with less common surnames, we also perform the analysis on the subsample of individuals with surnames that are less frequent than the median surname (column 8). The estimates of some coefficients are slightly larger. In this subsample, an increase of one standard deviation in all research indicators is associated with 10 percentage points higher chances of success. The presence of an advisor or a co-author in the committee has also a slightly larger impact. It increases candidates' chances of being promoted by 12 percentage points. The effect of colleagues and weak connections remains the same.

\subsection{Heterogeneity analysis}

Next we analyze whether the effect of connections varies depending on the characteristics of disciplines, universities, candidates and evaluators.

\subsubsection{Disciplines}

The Spanish academic profession is formally divided into nearly two hundred disciplines. We divide disciplines into seven broad groups: Physics and Mathematics, Engineering, Chemistry and Biology, Medicine, Social Sciences, Humanities, and Law. The upper panel of Table 6 shows some descriptive information by disciplinary group. Candidates' propensity to publish in journals indexed by ISI Web of Science varies across groups. In Law, candidates have almost no publications, suggesting that, at least in Spanish academia, ISI journals are not a common outlet for research in this disciplinary group. Candidates in the Social Sciences and Humanities have published less than one article (adjusted by the number of co-authors), whereas candidates in the rest of disciplines have published about five to nine articles.

The lower panel provides information on the impact of candidates' observable research quality and connections on their probability of being promoted. Indicators of research quality and connections tend to have a similar effect on candidates' chances of being promoted across all groups of disciplines. The only exception is observed in Law, where ISI publications and participation in dissertations do not seem to matter for promotion 
and the impact of having direct connections in the committee is twice as large as in the average discipline.

The size of the discipline may affect the prevalence of connections and also its impact. We divide observations in two groups according to the median number of tenured professors working in the discipline. Candidates in smaller disciplines have significantly more ties (upper panel of Table 7, columns 1-3). The expected number of strong connections in the committee is $56 \%$ larger (0.14 vs. 0.09 ), the number of colleagues is $40 \%$ larger (0.42 vs. 0.30$)$ and the number of weak ties is twice as large (0.33 vs. 0.15$)$. We also observe that strong connections are significantly more helpful in small disciplines, whereas the effect of colleagues and weak ties is statistically similar across disciplines of different size. Summing up, in small disciplines connections tend to be more abundant and more effective.

\subsubsection{Department size}

We explore whether the relevance of connections depends on the size of departments. The upper panel of Table 7, columns 4-6, provides information disaggregated for candidates whose expected number of colleagues in the committee was respectively below and above the median. Not surprisingly, candidates from larger departments tend to have more colleagues in the committee. They expect to have 0.65 colleagues in the evaluation committee, while the figure is eight times lower for candidates from smaller departments. Candidates from larger departments also tend to have a higher number of strong, weak and indirect ties. On the other hand, candidates from small departments benefit relatively more from the presence of colleagues in the committee. Their probability of success increases by 7 percentage points, twice as much as the effect for large departments. In total, candidates from large departments gain more from institutional connections, as their relative disadvantage in terms of the magnitude of the impact is more than compensated by their advantage in the expected number of colleagues in committees. 


\subsubsection{Candidates' characteristics}

Evaluators might feel more willing and more legitimized to support connected candidates of high quality. We proxy candidates' quality using a factor score, which is computed as a linear combination of publications, citations per publication, $\mathrm{PhD}$ theses advised, $\mathrm{PhD}$ committees and age, weighted by the estimated importance of each factor for promotion (Table 6). This factor score is normalized to have zero mean and unit standard deviation for all candidates in each exam.

Candidates of higher quality tend to have more professional connections but fewer institutional ones (lower panel of Table 7, columns 1-3). Better candidates benefit significantly more from their connections than candidates with a weaker research record. This is particularly true in the case of weak connections.

We also examine the role of candidates' gender. The lack of appropriate academic networks has been identified as one of the potential causes of women's failure to advance in their academic career (Blau et al. 2010). The evidence is consistent with this view. As shown in the middle panel of Table 7, columns 4-6, female candidates have fewer connections. Moreover, they benefit significantly less from the presence of strong connections in the evaluation committee.

\subsubsection{Evaluators' characteristics}

The importance of connections might also depend on evaluators' characteristics. Better researchers might be more committed to meritocratic evaluation. Alternatively, they might also be better able to impose their own evaluation criteria, being meritocratic or less so. In the latter case, better researchers might be relatively more effective in getting their connections promoted. We split connections in two groups according to whether the research quality of connected evaluators is below or above the average. The lower panel of Table 7, columns 1-3, reports the results of this analysis. All evaluators tend to overrate their connections in a similar way, independently of their research quality.

We also examine the effect of evaluators' gender. Male evaluators are significantly more effective at helping their former $\mathrm{PhD}$ students and their co-authors. The effect of 
weak links and colleagues is similar for both genders.

\subsection{Why do evaluators overrate connected candidates?}

There are several possible explanations for the positive effect of connections on promotion decisions. The evidence is consistent with the existence of favoritism, where personal relationships between candidates and evaluators lead to subjective evaluations. However, this is not the only possible explanation. Professors may differ in their criteria about which dimensions are more valuable. If professors are segregated across universities or professional networks according to their tastes, this might explain why evaluators prefer candidates they are acquainted with. Information asymmetries might also mediate the effect of connections. In a tournament where only a few candidates can be promoted, evaluators will optimally tend to select candidates whose quality they can observe more accurately (Cornell and Welch 1996). Evaluators may be better informed about the quality of acquainted candidates in dimensions that are not easily observable for other evaluators. Evaluators acquainted with candidates may be better informed about candidates' research pipeline, or about their contribution in co-authored papers. This might be particularly relevant for junior authors applying for AP positions. Information asymmetries may also be relevant in other dimensions. For instance, in exams to AP positions candidates were evaluated on their teaching quality. Evaluators from the same institution may have better information on this dimension.

While we cannot observe candidates' teaching quality, we can investigate the potential existence of information asymmetries in research. Using information on candidates' future research production, we examine whether evaluators select acquainted candidates with a stronger research potential, maybe compensating for their weaker publication record at the moment of the examination. Specifically, we estimate the following model:

$$
q_{i e}^{t}=\beta_{0}+\beta_{1}\left(c_{i e}-\mu_{i e}\right)+\epsilon_{i e}, \quad t=\{\text { pre-exam, post-exam }\}
$$

where $q_{i e}^{t}$ stands for promoted candidates' observable quality in period $t$. Pre-exam qual- 
ity includes information on dissertations and publications obtained before the evaluation took place. Post-exam quality corresponds to the five-year period following the evaluation. Again, quality is measured using a factor score that weighs publications, citations, participation in theses committees, and age based on the estimated contribution of each factor to promotion decisions (as reported in Table 6).

This analysis is reported in Table 8. Results differ depending on the nature of the connection. The evidence suggests that information asymmetries regarding candidates' research quality cannot justify the premium enjoyed by candidates who were evaluated by a strong professional connection or a colleague. These candidates tend to be significantly less productive, both before and after the evaluation, relative to other promoted candidates (columns 1 and 4).

However, in the case of weak ties the informational component seems to dominate any potential evaluation bias. Candidates who were promoted by a weak tie turn out to be more productive in the five-year period following the examination than other promoted candidates, although this effect is only marginally significant at standard levels. Given that information asymmetries about candidates' research potential are more likely to be present at earlier stages of the career, we analyze separately promotions to AP and FP positions. As expected, the informational contribution of weak ties is particularly large in AP exams. An additional weak tie is associated to future research quality being 0.25 standard deviations higher, an effect that is very significant both in statistical and economic terms (column 6).

\section{Conclusions}

The selection of evaluators is subject to a well-known dilemma. Evaluators who are acquainted with candidates may have superior information about their quality. Unfortunately, their criteria might also be biased. Which of the two effects dominates may vary depending on the nature of their relationship, on the extent of information asymmetries and on the institutional framework. 
In this paper we analyze the role of connections in the context of academic promotions in Spain. We focus on the period between 2002 and 2006, when a system of centralized competitions with random assignment of evaluators to committees was in place. We find that connections improve significantly candidates' chances of chances of success both in exams to associate professor positions and full professor positions. Connections affect promotion decisions in all scientific disciplines, but their effect is larger in small disciplines and for relatively better candidates. Their impact is comparable to observable research quality. For instance, the presence in the committee of a thesis advisor or a co-author is equivalent to a one standard deviation increase in candidate's number of publications, citations received, $\mathrm{PhD}$ students advised and participations in doctoral committees.

We test for the robustness of our results along several dimensions, including candidates' gender and quality. Men tend to be more connected and they also profit more from strong connections. ${ }^{18}$ Candidates with a relatively modest research profile benefit less from connections, particularly from weak ones.

The source of the premium associated to connections varies depending on the nature of the link. Among weak connections, the informational content of links dominates potential evaluation biases. Candidates who were promoted by a weak link, such as an evaluator who had participated in their thesis committee, turn out to be relatively more productive in the five-year period following the evaluation. On the contrary, candidates promoted by a strong professional or institutional connection are relatively less productive both before and after the evaluation, at least in terms of their observable research productivity. Potentially there might be information asymmetries in some other relevant dimension that is unobservable both to unconnected evaluators and to econometricians. However, the importance of this dimension and the scale of information asymmetries would have to be (perhaps unrealistically) large in order to fully explain the observed premium associated to strong and institutional connections. Alternatively, these candidates may be enjoying a preferential treatment.

\footnotetext{
${ }^{18}$ The lack of effective networks may be contributing to the lack of women in the upper levels of academia. In a companion paper we study in detail how committees' composition affect female professors' academic careers (Zinovyeva and Bagues 2011).
} 
In sum, the evidence suggests that there might be an optimal distance between evaluators and candidates. Weakly connected evaluators seem to be better informed about candidates' quality than evaluators who had no previous contact with candidates. Moreover, they appear to be less biased than strongly connected evaluators. Our results also indicate that this optimal distance may vary depending on the institutional framework. For instance, while Laband and Piette (1994) and Brogaard et al. (2012) find that editors use personal associations with colleagues in their departments in order to improve selection decisions, in Spain the presence of colleagues in promotion committees tends to decrease the research quality of promoted candidates.

Our analysis suggests that the introduction of centralized promotion examinations with random assignment of evaluators to committees per se does not eliminate the problem of favoritism. If anything, it introduces an element of randomness relative to who benefits from connections and who gets ultimately promoted. It also favors candidates from universities with relatively many senior researchers, which might be detrimental for the growth prospects of young departments. According to our findings, strong conflicts of interest should be prevented. If necessary, disciplines should be legally defined in such a way that they are large enough to allow for the implementation of the conflict of interest rules. At the same time, the presence of external evaluators who are weakly acquainted with the candidate may improve the quality of selection. Our work might be also interpreted as additional evidence in favor of a radical change in the way higher education is organized in continental Europe. The analysis of Aghion et al. (2010) suggests that a combination of competition and autonomy would make European universities more productive. According to this view, Europe needs to move from a system of rules to one of incentives, whereby it is in the self-interest of universities to appoint and promote the most productive individuals (Perotti 2002). Our analysis does not provide an answer about which of these alternatives, more rules or incentives, would yield better outcomes. Nevertheless, it illustrates the limitations of a system of centralized competitions where evaluators (and universities) do not internalize the consequences of their decisions. 


\section{References}

Aghion, Philippe, Mathias Dewatripont, Caroline Hoxby, Andreu Mas-Colell and André Sapir (2010), "The governance and performance of universities: evidence from Europe and the US," Economic Policy, Vol 25(61), pp. 7-59.

Blau, Francine D., Janet M. Curie, Rachel T.A. Croson and Donna K. Ginther (2010), "Can Mentoring Help Female Assistant Professors? Interim Results from a Randomized Trial," American Economic Review, Vol. 100(2), pp. 348-352.

Brogaard, Jonathan, Joseph Engelberg and Christopher A. Parsons (2012), "Network Position and Productivity: Evidence from Journal Editor Rotations," mimeo.

Combes, Pierre-Philippe, Laurent Linnemer and Michael Visser (2008), "Publish or peer-rich? The role of skills and networks in hiring economics professors," Labour Economics, Vol. 15, pp. 423-441.

Cornell, Bradford and Ivo Welch (1996), "Culture, Information, and Screening Discrimination," Journal of Political Economy, Vol. 104(3), pp. 542-571.

Cruz-Castro, Laura, Luis Sanz-Menéndez and Jaime Aja Valle (2006), "Las trayectorias profesionales y académicas de los profesores de universidad y los investigadores del CSIC," Unidad de políticas comparadas (CSIC) Working Paper \#06-08.

De Paola, Maria and Vincenzo Scoppa (2011), "Gender Discrimination and Evaluators' Gender: Evidence from the Italian Academy", Università di Calabria, Working Paper \#06 - 2011.

Durante, Ruben, Giovanna Labartino and Roberto Perotti (2011), "Academic Dynasties: Decentralization and Familism in the Italian Academia", NBER Working Paper \#17572.

Fuentes, Eulàlia and Llorenç Arguimbau (2010), "Las tesis doctorales en España (1997-2008): análisis, estadísticas y repositorios cooperativos", Revista Española de Documentación Científica, Vol. 33(1), pp. 63-89. 
Laband, David N. and Michael J. Piette (1994), "Favoritism versus Search for Good Papers: Empirical Evidence Regarding the Behavior of Journal Editors", Journal of Political Economy, Vol. 102(1), pp. 194-203.

Li, Danielle (2011), "Information, Bias, and Efficiency in Expert Evaluation: Evidence from the NIH", mimeo, MIT.

Granovetter, Mark S. (1973), "The Strength of Weak Ties", American Journal of Sociology, Vol. 78 (6), pp. 1360-1380.

Oettl, Alexander (2012), "Reconceptualizing Stars: Scientist Helpfulness and Peer Performance," Management Science, Vol. 58(6), pp. 1122-1140.

Perotti, Roberto (2002), "The Italian University System: Rules vs. Incentives", paper presented at the First Conference on Monitoring Italy, ISAE, Rome.

Sierra, Juan Carlos, Gualberto Buela-Casal, Mara Paz Bermudez Sánchez, and Pablo Santos-Iglesias (2009), "Opinión de Profesores Titulares y Catedráticos de Universidad acerca de criterios y estándares para la acreditación del profesorado universitario," Revista Española de Documentación Científica, Vol. 32 (3), pp. 89-100.

Stephan, Paula E. (1996), "The Economics of Science", Journal of Economic Literature, Vol. 34(3), pp. 1199-1235.

Zinovyeva, Natalia and Manuel Bagues (2011), "Does Gender Matter for Academic Promotion: Evidence from a Randomized Experiment", IZA Discussion Paper \#5537. 
Table 1: Descriptive statistics - Examinations

\begin{tabular}{lcccc}
\hline \hline & 1 & 2 & 3 & 4 \\
\hline & Mean & Std. Dev. & Min. & Max. \\
\hline \multirow{4}{*}{ Full professor exams } \\
\cline { 2 - 5 } Positions per exam & 2.92 & 1.78 & 1 & 12 \\
Candidates per exam & 27.12 & 17.99 & 3 & 132 \\
Proportion of positions filled & 0.98 & 0.09 & 0 & 1 \\
Number of exams & 502 & & & \\
\hline & \multicolumn{5}{c}{ Associate professor exams } \\
\cline { 2 - 5 } Positions per exam & 4.74 & 4.71 & 1 & 25 \\
Candidates per exam & 39.01 & 34.80 & 3 & 270 \\
Proportion of positions filled & 0.96 & 0.15 & 0 & 1 \\
Number of exams & 465 & & & \\
\hline
\end{tabular}

Table 2: Descriptive statistics - Eligible evaluators and candidates

\begin{tabular}{|c|c|c|c|c|}
\hline & 1 & 2 & 3 & 4 \\
\hline & \multicolumn{2}{|c|}{ Eligible evaluators } & \multicolumn{2}{|c|}{ Candidates } \\
\hline & $\begin{array}{c}\text { Full } \\
\text { professor }\end{array}$ & $\begin{array}{l}\text { Associate } \\
\text { professor }\end{array}$ & $\begin{array}{c}\text { Full } \\
\text { professor }\end{array}$ & $\begin{array}{l}\text { Associate } \\
\text { professor }\end{array}$ \\
\hline Age & $\begin{array}{l}52.91 \\
(6.41)\end{array}$ & $\begin{array}{l}44.98 \\
(7.82)\end{array}$ & $\begin{array}{l}46.39 \\
(6.50)\end{array}$ & $\begin{array}{l}37.45 \\
(6.55)\end{array}$ \\
\hline Female & $\begin{array}{c}0.14 \\
(0.35)\end{array}$ & $\begin{array}{c}0.35 \\
(0.48)\end{array}$ & $\begin{array}{c}0.27 \\
(0.44)\end{array}$ & $\begin{array}{c}0.40 \\
(0.49)\end{array}$ \\
\hline Publications, weighted by co-authors & $\begin{array}{c}9.01 \\
(12.74)\end{array}$ & $\begin{array}{c}4.80 \\
(7.40)\end{array}$ & $\begin{array}{c}5.46 \\
(7.65)\end{array}$ & $\begin{array}{c}3.03 \\
(5.74)\end{array}$ \\
\hline Citations per publication & $\begin{array}{c}8.13 \\
(9.94)\end{array}$ & $\begin{array}{c}7.56 \\
(11.62)\end{array}$ & $\begin{array}{c}7.67 \\
(12.33)\end{array}$ & $\begin{array}{c}6.51 \\
(13.38)\end{array}$ \\
\hline PhD students advised & $\begin{array}{c}5.19 \\
(5.33)\end{array}$ & $\begin{array}{l}1.25 \\
(2.15)\end{array}$ & $\begin{array}{c}2.01 \\
(2.74)\end{array}$ & $\begin{array}{c}0.24 \\
(0.90)\end{array}$ \\
\hline PhD committees & $\begin{array}{c}25.18 \\
(24.48)\end{array}$ & $\begin{array}{c}5.08 \\
(7.36)\end{array}$ & $\begin{array}{c}7.25 \\
(8.66)\end{array}$ & $\begin{array}{c}0.89 \\
(2.56)\end{array}$ \\
\hline Number of observations & 49199 & 61052 & 13612 & 18138 \\
\hline Number of individuals & 7963 & 21979 & 6545 & 10039 \\
\hline
\end{tabular}

Notes: Mean values, standard deviations in parentheses. 


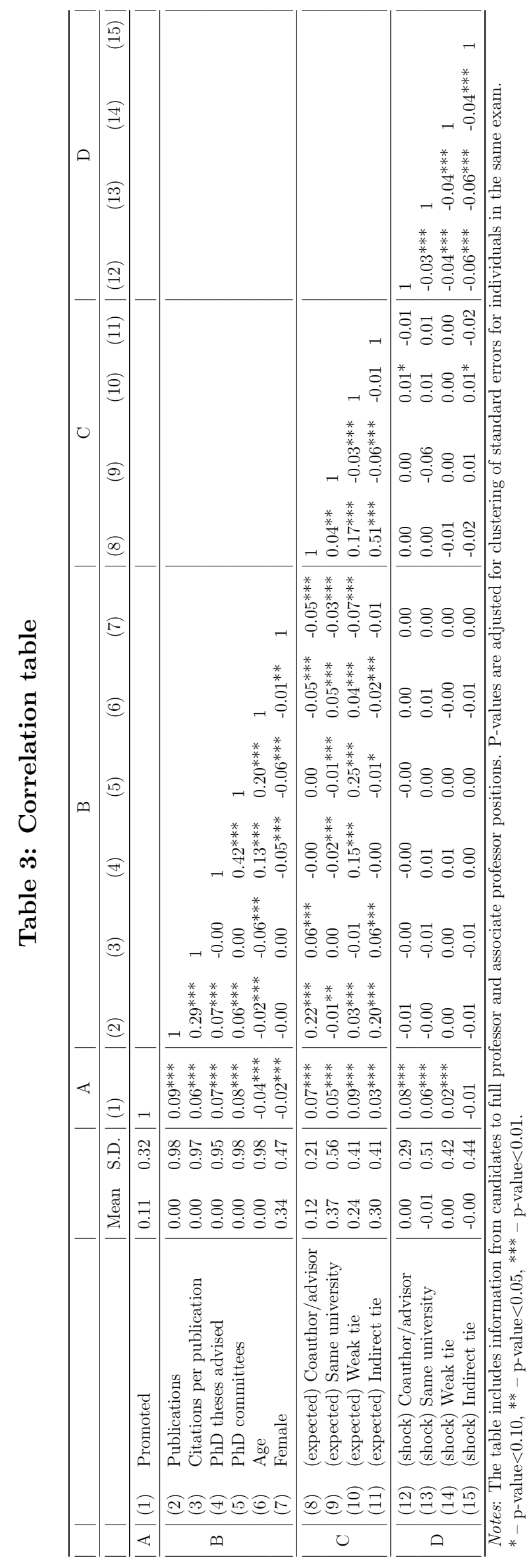


Table 4: Success rate, by committee composition

\begin{tabular}{|c|c|c|c|c|}
\hline & 1 & 2 & 3 & 4 \\
\hline & \multicolumn{2}{|c|}{ FP exams } & \multicolumn{2}{|c|}{ AP exams } \\
\hline & $\begin{array}{c}\text { Proportion, } \\
\%\end{array}$ & $\begin{array}{l}\text { Success } \\
\text { rate, } \%\end{array}$ & $\begin{array}{c}\text { Proportion, } \\
\%\end{array}$ & $\begin{array}{l}\text { Success } \\
\text { rate, } \%\end{array}$ \\
\hline No connection & 33 & 6 & 50 & 9 \\
\hline At least one connection: & 67 & 13 & 50 & 15 \\
\hline - Co-author/PhD advisor & 13 & 18 & 8 & 23 \\
\hline - Same university & 28 & 15 & 25 & 16 \\
\hline - Weak tie & 34 & 15 & 7 & 19 \\
\hline - Indirect tie & 21 & 11 & 24 & 12 \\
\hline
\end{tabular}

Notes: Columns 1 and 3 indicate the percentage of candidates that has a certain type of connection in the evaluation committee. Columns 2 and 4 provide information about their success rate. FP exams and AP exams stand for exams to Full and Associate Professor positions respectively. Candidates' average success rate is $11 \%$ in $\mathrm{FP}$ exams and $12 \%$ in $\mathrm{AP}$ exams.

Table 5: The effect of connections on candidates' success

\begin{tabular}{|c|c|c|c|c|c|c|c|c|}
\hline & 1 & 2 & 3 & 4 & 5 & 6 & 7 & 8 \\
\hline & All & FP exams & AP exams & All & All & $\begin{array}{l}\text { Graduated } \\
\text { in Spain }\end{array}$ & All & $\begin{array}{l}\text { Less } \\
\text { frequent } \\
\text { surnames }\end{array}$ \\
\hline \multicolumn{9}{|c|}{ Connections in committee (shock): } \\
\hline - Co-author/PhD advisor & $\begin{array}{c}0.088^{* * *} \\
(0.008)\end{array}$ & $\begin{array}{c}0.082^{* * *} \\
(0.010)\end{array}$ & $\begin{array}{c}0.094^{* * *} \\
(0.012)\end{array}$ & $\begin{array}{c}0.092^{* * *} \\
(0.008)\end{array}$ & $\begin{array}{c}0.074^{* * *} \\
(0.012)\end{array}$ & $\begin{array}{c}0.087^{* * *} \\
(0.009)\end{array}$ & $\begin{array}{c}0.089^{* * *} \\
(0.008)\end{array}$ & $\begin{array}{c}0.118^{* * *} \\
(0.012)\end{array}$ \\
\hline - Same university & $\begin{array}{c}0.040^{* * * *} \\
(0.004)\end{array}$ & $\begin{array}{c}0.038^{* * *} \\
(0.006)\end{array}$ & $\begin{array}{c}0.041^{* * *} \\
(0.006)\end{array}$ & $\begin{array}{c}0.043^{* * *} \\
(0.004)\end{array}$ & $\begin{array}{c}0.025^{* * *} \\
(0.007)\end{array}$ & $\begin{array}{c}0.041^{* * *} \\
(0.004)\end{array}$ & $\begin{array}{c}0.040^{* * * *} \\
(0.004)\end{array}$ & $\begin{array}{c}0.040^{* * *} \\
(0.005)\end{array}$ \\
\hline - Weak tie & $\begin{array}{c}0.021^{* * * *} \\
(0.005)\end{array}$ & $\begin{array}{c}0.017^{* * *} \\
(0.005)\end{array}$ & $\begin{array}{c}0.041^{* * *} \\
(0.011)\end{array}$ & $\begin{array}{c}0.025^{* * *} \\
(0.005)\end{array}$ & $\begin{array}{c}0.027^{* * *} \\
(0.008)\end{array}$ & $\begin{array}{c}0.019^{* * *} \\
(0.005)\end{array}$ & $\begin{array}{c}0.021^{* * *} \\
(0.005)\end{array}$ & $\begin{array}{c}0.023^{* * *} * \\
(0.007)\end{array}$ \\
\hline - Indirect tie & $\begin{array}{l}-0.001 \\
(0.004)\end{array}$ & $\begin{array}{c}0.004 \\
(0.006)\end{array}$ & $\begin{array}{l}-0.003 \\
(0.005)\end{array}$ & $\begin{array}{c}0.003 \\
(0.005)\end{array}$ & $\begin{array}{l}-0.003 \\
(0.007)\end{array}$ & $\begin{array}{l}-0.002 \\
(0.005)\end{array}$ & $\begin{array}{l}-0.001 \\
(0.004)\end{array}$ & $\begin{array}{c}0.000 \\
(0.006)\end{array}$ \\
\hline \multicolumn{9}{|c|}{ Quality indicators (normalized): } \\
\hline - Publications & & & & & & & $\begin{array}{c}0.023^{* * *} \\
(0.002)\end{array}$ & $\begin{array}{c}0.044^{* * *} \\
(0.004)\end{array}$ \\
\hline - Citations per publication & & & & & & & $\begin{array}{c}0.012^{\text {**** }} \\
(0.002)\end{array}$ & $\begin{array}{c}0.016^{* * * *} \\
(0.003)\end{array}$ \\
\hline - PhD theses advised & & & & & & & $\begin{array}{c}0.016^{* * *} \\
(0.002)\end{array}$ & $\begin{array}{c}0.017^{* * *} * \\
(0.003)\end{array}$ \\
\hline - PhD committees & & & & & & & $\begin{array}{c}0.021^{* * *} \\
(0.002)\end{array}$ & $\begin{array}{c}0.023^{* * *} * \\
(0.003)\end{array}$ \\
\hline - Age & & & & & & & $\begin{array}{c}-0.019^{* * *} \\
(0.002)\end{array}$ & $\begin{array}{c}-0.019^{* * * *} \\
(0.002)\end{array}$ \\
\hline Constant & $\begin{array}{c}0.113 \text { *** } \\
(0.002)\end{array}$ & $\begin{array}{c}0.106^{* * *} \\
(0.003)\end{array}$ & $\begin{array}{c}0.118^{* * *} \\
(0.003)\end{array}$ & $\begin{array}{c}0.113^{* * *} \\
(0.000)\end{array}$ & $\begin{array}{c}0.113^{* * *} \\
(0.003)\end{array}$ & $\begin{array}{c}0.114^{* * *} \\
(0.002)\end{array}$ & $\begin{array}{c}0.113^{* * * *} \\
(0.002)\end{array}$ & $\begin{array}{c}0.128^{* * *} * \\
(0.003)\end{array}$ \\
\hline Exam dummies & & & & Yes & & & & \\
\hline Individual dummies & & & & & Yes & & & \\
\hline Adjusted R-squared & 0.011 & 0.011 & 0.011 & 0.016 & 0.200 & 0.011 & 0.030 & 0.043 \\
\hline Number of observations & 31750 & 13612 & 18138 & 31750 & 31750 & 24638 & 31750 & 16168 \\
\hline \multicolumn{9}{|c|}{$\begin{array}{l}\text { Notes: OLS estimates, standard errors clustered by exam are reported in parentheses. Coefficients indicate the percentage-point } \\
\text { increase in the success rate associated to a (random) increase in the number of connected evaluators (in a seven-member committee). } \\
\text { FP exams and AP exams stand for exams to Full and Associate Professor positions respectively. Column } 6 \text { only includes candidates } \\
\text { who did their PhD in Spain. Quality measures are normalized for candidates in the same exam. The subsample of individuals with } \\
\text { "less frequent surnames" includes individuals whose paternal and maternal surname have a frequency inferior to } 100,000 \text { (source: } \\
\text { Spanish Statistical Institute). } \\
*_{-}^{*} \text { - p-value }<0.10,{ }^{* *} \text { - p-value }<0.05, * *{ }_{-}^{*} \text { - p-value }<0.01 \text {. }\end{array}$} \\
\hline
\end{tabular}


Table 6: The effect of connections on candidates' success, by disciplinary group

\begin{tabular}{|c|c|c|c|c|c|c|c|}
\hline & 1 & 2 & 3 & 4 & 5 & 6 & 7 \\
\hline & \multicolumn{7}{|c|}{ Disciplinary group: } \\
\hline & $\begin{array}{l}\text { Physics } \\
\text { and Math }\end{array}$ & Engineering & $\begin{array}{l}\text { Chemistry } \\
\text { and Biology }\end{array}$ & Medicine & $\begin{array}{c}\text { Social } \\
\text { Sciences }\end{array}$ & Humanities & Law \\
\hline \multicolumn{8}{|l|}{ Means } \\
\hline \multicolumn{8}{|l|}{ Connections in committee: } \\
\hline \multicolumn{8}{|c|}{ Quality indicators (non-normalized): } \\
\hline \multicolumn{8}{|l|}{ Effect on success } \\
\hline \multicolumn{8}{|c|}{ Connections in committee (shock): } \\
\hline - Co-author/PhD advisor & $\begin{array}{c}0.099^{* * *} \\
(0.020)\end{array}$ & $\begin{array}{c}0.104^{* * *} \\
(0.019)\end{array}$ & $\begin{array}{c}0.047^{* * * *} \\
(0.016)\end{array}$ & $\begin{array}{c}0.072^{* * *} \\
(0.013)\end{array}$ & $\begin{array}{c}0.092^{* * *} \\
(0.032)\end{array}$ & $\begin{array}{c}0.142^{* * * *} \\
(0.030)\end{array}$ & $\begin{array}{c}0.213^{* * *} \\
(0.039)\end{array}$ \\
\hline - Same university & $\begin{array}{c}0.022^{* *} \\
(0.010)\end{array}$ & $\begin{array}{c}0.019 * * \\
(0.009)\end{array}$ & $\begin{array}{c}0.042^{* * * *} \\
(0.011)\end{array}$ & $\begin{array}{c}0.042^{* * * *} \\
(0.011)\end{array}$ & $\begin{array}{c}0.032 * * \\
(0.012)\end{array}$ & $\begin{array}{c}0.044^{* * *} \\
(0.008)\end{array}$ & $\begin{array}{c}0.106^{* * *} \\
(0.015)\end{array}$ \\
\hline - Weak tie & $\begin{array}{c}0.023 \\
(0.017)\end{array}$ & $\begin{array}{c}0.015 \\
(0.013)\end{array}$ & $\begin{array}{c}0.029 * * \\
(0.013)\end{array}$ & $\begin{array}{l}0.027^{*} \\
(0.014)\end{array}$ & $\begin{array}{c}0.007 \\
(0.013)\end{array}$ & $\begin{array}{c}0.027^{* *} \\
(0.011)\end{array}$ & $\begin{array}{c}0.014 \\
(0.010)\end{array}$ \\
\hline - Citations per publication & $\begin{array}{c}0.018^{* * * *} \\
(0.004)\end{array}$ & $\begin{array}{c}0.006 \\
(0.005)\end{array}$ & $\begin{array}{c}0.023^{* * *} \\
(0.005)\end{array}$ & $\begin{array}{c}0.018^{* * *} \\
(0.005)\end{array}$ & $\begin{array}{l}0.011^{*} \\
(0.006)\end{array}$ & $\begin{array}{c}0.006 \\
(0.006)\end{array}$ & $\begin{array}{l}-0.002 \\
(0.005)\end{array}$ \\
\hline - PhD theses advised & $\begin{array}{c}0.016^{* * *} \\
(0.005)\end{array}$ & $\begin{array}{l}0.010^{*} \\
(0.006)\end{array}$ & $\begin{array}{c}0.028^{* * *} \\
(0.006)\end{array}$ & $\begin{array}{c}0.026^{* * *} \\
(0.006)\end{array}$ & $\begin{array}{c}0.005 \\
(0.006)\end{array}$ & $\begin{array}{c}0.018^{* *} \\
(0.007)\end{array}$ & $\begin{array}{c}0.004 \\
(0.007)\end{array}$ \\
\hline - PhD committees & $\begin{array}{c}0.013^{* * *} \\
(0.005)\end{array}$ & $\begin{array}{c}0.017^{* *} \\
(0.007)\end{array}$ & $\begin{array}{c}0.020^{* * *} \\
(0.006)\end{array}$ & $\begin{array}{c}0.020^{* * *} \\
(0.006)\end{array}$ & $\begin{array}{c}0.028^{* * *} \\
(0.007)\end{array}$ & $\begin{array}{c}0.031^{* * * *} \\
(0.006)\end{array}$ & $\begin{array}{c}0.013^{* *} \\
(0.006)\end{array}$ \\
\hline - Age & $\begin{array}{c}-0.014^{* * *} \\
(0.004)\end{array}$ & $\begin{array}{c}-0.033^{* * *} \\
(0.004)\end{array}$ & $\begin{array}{c}-0.015^{* * *} \\
(0.005)\end{array}$ & $\begin{array}{c}-0.016^{* * *} \\
(0.005)\end{array}$ & $\begin{array}{c}-0.020^{* * *} \\
(0.004)\end{array}$ & $\begin{array}{c}-0.010^{* *} \\
(0.005)\end{array}$ & $\begin{array}{c}-0.026^{* * *} \\
(0.005)\end{array}$ \\
\hline Constant & $\begin{array}{c}0.089^{* * *} \\
(0.005)\end{array}$ & $\begin{array}{c}0.118^{* * *} \\
(0.005)\end{array}$ & $\begin{array}{c}0.125^{* * *} \\
(0.007)\end{array}$ & $\begin{array}{c}0.103^{* * *} \\
(0.006)\end{array}$ & $\begin{array}{c}0.115^{* * *} \\
(0.006)\end{array}$ & $\begin{array}{c}0.141^{* * *} \\
(0.004)\end{array}$ & $\begin{array}{c}0.087^{* * *} \\
(0.006)\end{array}$ \\
\hline Adjusted R-squared & 0.033 & 0.027 & 0.031 & 0.046 & 0.034 & 0.030 & 0.051 \\
\hline Number of observations & 5227 & 4596 & 4023 & 4120 & 4073 & 6254 & 3457 \\
\hline
\end{tabular}


Table 7: Heterogeneity analysis

\begin{tabular}{|c|c|c|c|c|c|c|}
\hline & 1 & 2 & 3 & 4 & 5 & 6 \\
\hline & \multicolumn{3}{|c|}{ Discipline size: } & \multicolumn{3}{|c|}{ Department size: } \\
\hline & $\leq$ median & $>$ median & Difference & $\leq$ median & $>$ median & Difference \\
\hline \multicolumn{7}{|l|}{ Means } \\
\hline $\begin{array}{l}\text { Connections in committee: } \\
\text { - Co-author/PhD advisor } \\
\text { - Same university } \\
\text { - Weak tie } \\
\text { - Indirect tie }\end{array}$ & $\begin{array}{l}0.14 \\
0.42 \\
0.33 \\
0.29\end{array}$ & $\begin{array}{l}0.09 \\
0.30 \\
0.15 \\
0.31\end{array}$ & $\begin{array}{c}0.05^{* * *} \\
0.11^{* * *} \\
0.18^{* * *} \\
-0.02^{* * *}\end{array}$ & $\begin{array}{l}0.08 \\
0.08 \\
0.22 \\
0.27\end{array}$ & $\begin{array}{l}0.15 \\
0.65 \\
0.27 \\
0.32\end{array}$ & $\begin{array}{l}-0.07^{* * *} * \\
-0.57^{* * *} \\
-0.04^{* * *} \\
-0.05^{* * *}\end{array}$ \\
\hline \multicolumn{7}{|l|}{ Effect on success } \\
\hline $\begin{array}{l}\text { Connections in committee (shock): } \\
\text { - Co-author/PhD advisor }\end{array}$ & $\begin{array}{c}0.106^{* * *} \\
(0.010)\end{array}$ & $\begin{array}{c}0.062^{* * *} \\
(0.010)\end{array}$ & $\begin{array}{c}0.043^{* * *} \\
(0.015)\end{array}$ & $\begin{array}{c}0.079^{* * *} \\
(0.012)\end{array}$ & $\begin{array}{c}0.093^{* * *} \\
(0.010)\end{array}$ & $\begin{array}{l}-0.014 \\
(0.016)\end{array}$ \\
\hline - Same university & $\begin{array}{c}0.042^{* * *} \\
(0.005)\end{array}$ & $\begin{array}{c}0.036^{* * *} \\
(0.006)\end{array}$ & $\begin{array}{c}0.007 \\
(0.008)\end{array}$ & $\begin{array}{c}0.069^{* * *} \\
(0.011)\end{array}$ & $\begin{array}{c}0.036^{* * *} \\
(0.004)\end{array}$ & $\begin{array}{c}0.032^{* * *} \\
(0.011)\end{array}$ \\
\hline - Weak tie & $\begin{array}{c}0.021^{* * *} \\
(0.006)\end{array}$ & $\begin{array}{c}0.022^{* * * *} \\
(0.008)\end{array}$ & $\begin{array}{l}-0.001 \\
(0.010)\end{array}$ & $\begin{array}{c}0.025^{* * * *} \\
(0.007)\end{array}$ & $\begin{array}{c}0.018^{* * * *} \\
(0.007)\end{array}$ & $\begin{array}{c}0.008 \\
(0.010)\end{array}$ \\
\hline - Indirect tie & $\begin{array}{l}-0.003 \\
(0.006)\end{array}$ & $\begin{array}{l}-0.000 \\
(0.006)\end{array}$ & $\begin{array}{c}0.003 \\
(0.008)\end{array}$ & $\begin{array}{c}0.000 \\
(0.006)\end{array}$ & $\begin{array}{l}-0.001 \\
(0.006)\end{array}$ & $\begin{array}{l}-0.002 \\
(0.008)\end{array}$ \\
\hline Constant & $\begin{array}{c}0.129^{* * *} \\
(0.003)\end{array}$ & $\begin{array}{c}0.096^{* * *} \\
(0.003)\end{array}$ & $\begin{array}{c}0.032^{* * *} \\
(0.004)\end{array}$ & $\begin{array}{c}0.096^{* * *} \\
(0.003)\end{array}$ & $\begin{array}{c}0.130^{* * *} \\
(0.003)\end{array}$ & $\begin{array}{c}-0.034^{* * *} \\
(0.004)\end{array}$ \\
\hline \multirow[t]{3}{*}{ Number of observations } & 16153 & 15597 & & 15876 & 15874 & \\
\hline & \multicolumn{3}{|c|}{ Quality of candidates: } & \multicolumn{3}{|c|}{ Gender of candidates: } \\
\hline & $\leq$ median & $\geq$ median & Difference & Male & Female & Difference \\
\hline \multicolumn{7}{|l|}{ Means } \\
\hline \multirow{2}{*}{\multicolumn{7}{|c|}{$\begin{array}{l}\text { Connections in committee: } \\
\text { - Coauthor/PhD advisor } \\
\text { - Same university } \\
\text { - Weak tie } \\
\text { - Indirect tie } \\
\text { Effect on success }\end{array}$}} \\
\hline & & & & & & \\
\hline $\begin{array}{l}\text { Connections in committee (shock): } \\
\text { - Coauthor/PhD advisor }\end{array}$ & $\begin{array}{c}0.073^{* * *} * \\
(0.011)\end{array}$ & $\begin{array}{c}0.101^{* * * *} \\
(0.011)\end{array}$ & $\begin{array}{l}-0.027^{*} \\
(0.015)\end{array}$ & $\begin{array}{c}0.099^{* * * *} \\
(0.009)\end{array}$ & $\begin{array}{c}0.064^{* * *} \\
(0.013)\end{array}$ & $\begin{array}{c}0.034^{* *} \\
(0.015)\end{array}$ \\
\hline - Same university & $\begin{array}{c}0.034^{* * *} \\
(0.005)\end{array}$ & $\begin{array}{c}0.049^{* * *} \\
(0.007)\end{array}$ & $\begin{array}{l}-0.015^{*} \\
(0.008)\end{array}$ & $\begin{array}{c}0.038^{* * * *} \\
(0.005)\end{array}$ & $\begin{array}{c}0.043^{* * *} \\
(0.007)\end{array}$ & $\begin{array}{l}-0.006 \\
(0.008)\end{array}$ \\
\hline - Weak tie & $\begin{array}{l}0.011^{*} \\
(0.006)\end{array}$ & $\begin{array}{c}0.028^{* * *} \\
(0.007)\end{array}$ & $\begin{array}{l}-0.017^{*} \\
(0.009)\end{array}$ & $\begin{array}{c}0.023^{* * *} * \\
(0.006)\end{array}$ & $\begin{array}{l}0.017^{*} \\
(0.009)\end{array}$ & $\begin{array}{c}0.006 \\
(0.011)\end{array}$ \\
\hline - Indirect tie & $\begin{array}{l}-0.004 \\
(0.005)\end{array}$ & $\begin{array}{c}0.002 \\
(0.006)\end{array}$ & $\begin{array}{l}-0.006 \\
(0.008)\end{array}$ & $\begin{array}{c}0.000 \\
(0.005)\end{array}$ & $\begin{array}{l}-0.002 \\
(0.007)\end{array}$ & $\begin{array}{c}0.002 \\
(0.009)\end{array}$ \\
\hline Constant & $\begin{array}{l}0.077^{* * *} \\
(0.002)\end{array}$ & $\begin{array}{c}0.151^{* * *} \\
(0.003)\end{array}$ & $\begin{array}{c}-0.074^{* * *} \\
(0.004)\end{array}$ & $\begin{array}{l}0.117^{* * * *} \\
(0.003)\end{array}$ & $\begin{array}{l}0.106^{* * *} \\
(0.003)\end{array}$ & $\begin{array}{c}0.011^{* * *} \\
(0.004)\end{array}$ \\
\hline \multirow[t]{3}{*}{ Number of observations } & 16220 & 15530 & & 20901 & 10849 & \\
\hline & \multicolumn{3}{|c|}{ Quality of connected evaluators: } & \multicolumn{3}{|c|}{ Gender of connected evaluators: } \\
\hline & $\leq$ median & $\geq$ median & Difference & Male & Female & Difference \\
\hline \multicolumn{7}{|l|}{ Effect on success } \\
\hline $\begin{array}{l}\text { Connections in committee (shock): } \\
\text { - Coauthor/PhD advisor }\end{array}$ & $\begin{array}{l}0.090^{* * *} \\
(0.013)\end{array}$ & $\begin{array}{l}0.081^{* * *} \\
(0.009)\end{array}$ & $\begin{array}{c}0.009 \\
(0.016)\end{array}$ & $\begin{array}{l}0.095^{* * *} \\
(0.008)\end{array}$ & $\begin{array}{l}0.033^{*} \\
(0.019)\end{array}$ & $\begin{array}{c}0.062^{* * *} \\
(0.021)\end{array}$ \\
\hline - Same university & $\begin{array}{c}0.039^{* * *} * \\
(0.005)\end{array}$ & $\begin{array}{l}0.031^{* * *} \\
(0.005)\end{array}$ & $\begin{array}{c}0.008 \\
(0.007)\end{array}$ & $\begin{array}{c}0.037^{* * *} * \\
(0.004)\end{array}$ & $\begin{array}{l}0.036^{* * *} \\
(0.010)\end{array}$ & $\begin{array}{c}0.001 \\
(0.011)\end{array}$ \\
\hline - Weak tie & $\begin{array}{c}0.015^{*} \\
(0.008)\end{array}$ & $\begin{array}{c}0.020^{* * *} \\
(0.006)\end{array}$ & $\begin{array}{l}-0.005 \\
(0.010)\end{array}$ & $\begin{array}{c}0.019^{* * *} \\
(0.005)\end{array}$ & $\begin{array}{c}0.030^{* *} \\
(0.014)\end{array}$ & $\begin{array}{l}-0.011 \\
(0.015)\end{array}$ \\
\hline - Indirect tie & $\begin{array}{l}-0.005 \\
(0.007)\end{array}$ & $\begin{array}{l}-0.004 \\
(0.005)\end{array}$ & $\begin{array}{l}-0.001 \\
(0.008)\end{array}$ & $\begin{array}{c}0.000 \\
(0.004)\end{array}$ & $\begin{array}{l}-0.012 \\
(0.010)\end{array}$ & $\begin{array}{c}0.012 \\
(0.011)\end{array}$ \\
\hline Constant & $\begin{array}{c}0.113^{* * *} \\
(0.002)\end{array}$ & $\begin{array}{c}0.113^{* * *} \\
(0.002)\end{array}$ & $\begin{array}{c}0.000 \\
(0.004)\end{array}$ & $\begin{array}{c}0.113^{* * *} \\
(0.002)\end{array}$ & $\begin{array}{c}0.113^{* * *} \\
(0.002)\end{array}$ & $\begin{array}{c}0.000 \\
(0.004)\end{array}$ \\
\hline Number of observations & 31750 & 31750 & & 31750 & 31750 & \\
\hline
\end{tabular}

Notes: The panel "Means" provides information on the mean of the corresponding variables. The panel "Effect on success" reports OLS estimates, standard errors clustered by exam are in parentheses. "Quality" is a factor score computed as a linear combination of (normalized) publications, citations per publication, $\mathrm{PhD}$ theses advised, participation in PhD committees and age, weighted by the estimated importance of each factor for promotion in the corresponding disciplinary group, as reported in Table 6. By construction, the mean of candidates' "quality" is zero; variance is normalized to one. $*^{*}$ - p-value $<0.10, * *-$ p-value $<0.05, * * *-$ p-value $<0.01$. 
Table 8: Quality of promoted candidates

\begin{tabular}{|c|c|c|c|c|c|c|}
\hline & 1 & 2 & 3 & 4 & 5 & 6 \\
\hline & \multicolumn{3}{|c|}{ Pre-exam quality } & \multicolumn{3}{|c|}{ Post-exam quality } \\
\hline & All & FP exams & AP exams & All & FP exams & AP exams \\
\hline \multicolumn{7}{|c|}{ Connections in committee (shock): } \\
\hline - Co-author/PhD advisor & $\begin{array}{c}-0.070^{*} \\
(0.040)\end{array}$ & $\begin{array}{l}-0.075 \\
(0.062)\end{array}$ & $\begin{array}{l}-0.076 \\
(0.053)\end{array}$ & $\begin{array}{c}-0.088^{* *} \\
(0.043)\end{array}$ & $\begin{array}{c}0.002 \\
(0.066)\end{array}$ & $\begin{array}{c}-0.160^{* * *} \\
(0.056)\end{array}$ \\
\hline - Same university & $\begin{array}{c}-0.066^{* *} \\
(0.030)\end{array}$ & $\begin{array}{l}-0.072 \\
(0.048)\end{array}$ & $\begin{array}{l}-0.067^{*} \\
(0.038)\end{array}$ & $\begin{array}{c}-0.092^{* * *} \\
(0.033)\end{array}$ & $\begin{array}{l}-0.062 \\
(0.048)\end{array}$ & $\begin{array}{c}-0.113^{* *} \\
(0.045)\end{array}$ \\
\hline - Weak tie & $\begin{array}{c}0.026 \\
(0.037)\end{array}$ & $\begin{array}{l}-0.021 \\
(0.042)\end{array}$ & $\begin{array}{l}0.141^{*} \\
(0.076)\end{array}$ & $\begin{array}{c}0.071^{*} \\
(0.036)\end{array}$ & $\begin{array}{c}0.013 \\
(0.041)\end{array}$ & $\begin{array}{c}0.251^{* * *} \\
(0.073)\end{array}$ \\
\hline - Indirect tie & $\begin{array}{c}0.022 \\
(0.038)\end{array}$ & $\begin{array}{l}-0.062 \\
(0.064)\end{array}$ & $\begin{array}{c}0.060 \\
(0.047)\end{array}$ & $\begin{array}{l}-0.013 \\
(0.038)\end{array}$ & $\begin{array}{l}-0.020 \\
(0.073)\end{array}$ & $\begin{array}{c}-0.009 \\
(0.044)\end{array}$ \\
\hline Constant & $\begin{array}{c}0.417^{* * *} \\
(0.018)\end{array}$ & $\begin{array}{c}0.523^{* * *} \\
(0.027)\end{array}$ & $\begin{array}{c}0.345^{* * *} \\
(0.023)\end{array}$ & $\begin{array}{c}0.458^{* * *} \\
(0.017)\end{array}$ & $\begin{array}{c}0.485^{* * *} \\
(0.026)\end{array}$ & $\begin{array}{c}0.438^{* * *} \\
(0.022)\end{array}$ \\
\hline Adjusted R-squared & 0.001 & -0.000 & 0.003 & 0.004 & -0.001 & 0.011 \\
\hline Number of observations & 3573 & 1446 & 2127 & 3573 & 1446 & 2127 \\
\hline
\end{tabular}

Notes: OLS estimates, standard errors clustered by exam are reported in parentheses. "Quality" is a factor score computed as a linear combination of (normalized) publications, citations per publication, $\mathrm{PhD}$ theses advised, participation in $\mathrm{PhD}$ committees and age, weighted by the estimated importance of each factor for promotion in the corresponding disciplinary group, as reported in Table 6. By construction, the mean of candidates' "quality" is zero; variance is normalized to one. "Pre-exam quality" includes information on dissertations and publications obtained before or during the year when the evaluation took place. "Post-exam quality" corresponds to the five-year period following the evaluation.

$*_{\text {- }}$-value $<0.10, * *$ - p-value $<0.05, * * *-$ p-value $<0.01$.

Table A1: The role of connections, by type of connection

\begin{tabular}{|c|c|c|c|c|c|c|c|c|c|c|c|c|}
\hline & 1 & 2 & 3 & 4 & 5 & 6 & 7 & 8 & 9 & 10 & 11 & 12 \\
\hline & \multicolumn{3}{|c|}{ Means } & \multicolumn{3}{|c|}{$\begin{array}{l}\text { The effect of connections } \\
\text { on candidates' success }\end{array}$} & \multicolumn{3}{|c|}{$\begin{array}{l}\text { Pre-exam quality of } \\
\text { promoted candidates }\end{array}$} & \multicolumn{3}{|c|}{$\begin{array}{l}\text { Post-exam quality of } \\
\text { promoted candidates }\end{array}$} \\
\hline & All & $\mathrm{FP}$ & $\mathrm{AP}$ & All & $\mathrm{FP}$ & AP & All & $\mathrm{FP}$ & $\mathrm{AP}$ & All & FP & $\mathrm{AP}$ \\
\hline \multicolumn{13}{|l|}{ Strong connection: } \\
\hline - PhD advisor & 3 & 3 & 3 & $\begin{array}{c}0.141 * * * \\
(0.014)\end{array}$ & $\begin{array}{c}0.098^{* * *} \\
(0.020)\end{array}$ & $\begin{array}{c}0.173 * * * \\
(0.019)\end{array}$ & $\begin{array}{c}-0.186^{* * *} \\
(0.065)\end{array}$ & $\begin{array}{l}-0.190 \\
(0.128)\end{array}$ & $\begin{array}{c}-0.156^{* *} \\
(0.074)\end{array}$ & $\begin{array}{l}-0.074 \\
(0.073)\end{array}$ & $\begin{array}{c}0.015 \\
(0.153)\end{array}$ & $\begin{array}{l}-0.102 \\
(0.080)\end{array}$ \\
\hline - Co-author & 8 & 10 & 6 & $\begin{array}{c}0.065^{* * * *} \\
(0.009)\end{array}$ & $\begin{array}{c}0.077^{* * * *} \\
(0.011)\end{array}$ & $\begin{array}{c}0.051^{* * * *} \\
(0.013)\end{array}$ & $\begin{array}{l}-0.005 \\
(0.051)\end{array}$ & $\begin{array}{l}-0.036 \\
(0.069)\end{array}$ & $\begin{array}{l}-0.015 \\
(0.075)\end{array}$ & $\begin{array}{l}-0.100^{*} \\
(0.052)\end{array}$ & $\begin{array}{l}-0.009 \\
(0.073)\end{array}$ & $\begin{array}{c}-0.206^{* * *} \\
(0.073)\end{array}$ \\
\hline \multicolumn{13}{|l|}{ Institutional connection: } \\
\hline - Same university & 26 & 28 & 25 & $\begin{array}{c}0.040^{* * *} \\
(0.004)\end{array}$ & $\begin{array}{c}0.038^{* * *} \\
(0.006)\end{array}$ & $\begin{array}{c}0.041 * * * \\
(0.006)\end{array}$ & $\begin{array}{c}-0.065^{* *} \\
(0.030)\end{array}$ & $\begin{array}{l}-0.070 \\
(0.048)\end{array}$ & $\begin{array}{c}-0.069^{*} \\
(0.038)\end{array}$ & $\begin{array}{c}-0.090^{* * *} \\
(0.033)\end{array}$ & $\begin{array}{l}-0.062 \\
(0.049)\end{array}$ & $\begin{array}{c}-0.115^{* *} \\
(0.044)\end{array}$ \\
\hline \multicolumn{13}{|l|}{ Weak tie: } \\
\hline $\begin{array}{l}\text { - PhD thesis committee } \\
\text { member }\end{array}$ & 7 & 9 & 5 & $\begin{array}{c}0.029^{* * *} \\
(0.008)\end{array}$ & $\begin{array}{c}0.021^{* *} \\
(0.010)\end{array}$ & $\begin{array}{c}0.042^{* * *} \\
(0.013)\end{array}$ & $\begin{array}{c}0.002 \\
(0.059)\end{array}$ & $\begin{array}{l}-0.039 \\
(0.086)\end{array}$ & $\begin{array}{c}0.032 \\
(0.081)\end{array}$ & $\begin{array}{c}0.130^{* *} \\
(0.060)\end{array}$ & $\begin{array}{c}0.100 \\
(0.085)\end{array}$ & $\begin{array}{l}0.148^{*} \\
(0.084)\end{array}$ \\
\hline - Link by invitation & 4 & 8 & 0.5 & $\begin{array}{c}0.043^{* * * *} \\
(0.012)\end{array}$ & $\begin{array}{c}0.045^{* * * *} \\
(0.013)\end{array}$ & $\begin{array}{l}0.020 \\
(0.046)\end{array}$ & $\begin{array}{l}0.015 \\
(0.076)\end{array}$ & $\begin{array}{l}-0.057 \\
(0.071)\end{array}$ & $\begin{array}{l}0.427 \\
(0.324)\end{array}$ & $\begin{array}{l}0.002 \\
(0.070)\end{array}$ & $\begin{array}{l}-0.062 \\
(0.068)\end{array}$ & $\begin{array}{l}0.564^{* *} \\
(0.281)\end{array}$ \\
\hline - Same PhD thesis committee & 10 & 21 & 2 & $\begin{array}{c}0.009 \\
(0.007)\end{array}$ & $\begin{array}{l}0.006 \\
(0.007)\end{array}$ & $\begin{array}{l}0.046^{*} \\
(0.025)\end{array}$ & $\begin{array}{c}0.049 \\
(0.054)\end{array}$ & $\begin{array}{l}0.010 \\
(0.055)\end{array}$ & $\begin{array}{l}0.326^{*} \\
(0.172)\end{array}$ & $\begin{array}{l}0.069 \\
(0.050)\end{array}$ & $\begin{array}{c}0.025 \\
(0.053)\end{array}$ & $\begin{array}{c}0.440^{* * * *} \\
(0.146)\end{array}$ \\
\hline \multicolumn{13}{|l|}{ Indirect tie: } \\
\hline - Same PhD advisor & 0.3 & 0.3 & 0.2 & $\begin{array}{c}0.048 \\
(0.046)\end{array}$ & $\begin{array}{c}0.089 \\
(0.086)\end{array}$ & $\begin{array}{c}0.023 \\
(0.053)\end{array}$ & $\begin{array}{l}-0.338 \\
(0.334)\end{array}$ & $\begin{array}{c}-1.291^{* * *} \\
(0.346)\end{array}$ & $\begin{array}{c}0.286 \\
(0.479)\end{array}$ & $\begin{array}{c}-0.456^{*} \\
(0.271)\end{array}$ & $\begin{array}{l}-0.673 \\
(0.426)\end{array}$ & $\begin{array}{l}-0.331 \\
(0.393)\end{array}$ \\
\hline - Same co-author & 14 & 12 & 15 & $\begin{array}{l}-0.002 \\
(0.006)\end{array}$ & $\begin{array}{c}0.005 \\
(0.009)\end{array}$ & $\begin{array}{l}-0.006 \\
(0.007)\end{array}$ & $\begin{array}{l}-0.007 \\
(0.052)\end{array}$ & $\begin{array}{l}-0.096 \\
(0.088)\end{array}$ & $\begin{array}{c}0.035 \\
(0.065)\end{array}$ & $\begin{array}{l}-0.068 \\
(0.052)\end{array}$ & $\begin{array}{l}-0.143 \\
(0.103)\end{array}$ & $\begin{array}{l}-0.032 \\
(0.060)\end{array}$ \\
\hline $\begin{array}{l}\text { - Same PhD thesis committee } \\
\text { member }\end{array}$ & 8 & 8 & 9 & $\begin{array}{c}0.001 \\
(0.007)\end{array}$ & $\begin{array}{c}0.005 \\
(0.011)\end{array}$ & $\begin{array}{c}-0.002 \\
(0.009)\end{array}$ & $\begin{array}{c}0.084 \\
(0.054)\end{array}$ & $\begin{array}{c}0.040 \\
(0.101)\end{array}$ & $\begin{array}{c}0.088 \\
(0.063)\end{array}$ & $\begin{array}{c}0.086 \\
(0.056)\end{array}$ & $\begin{array}{c}0.210^{* *} \\
(0.104)\end{array}$ & $\begin{array}{c}0.032 \\
(0.065)\end{array}$ \\
\hline Constant & & & & $\begin{array}{c}0.113^{* * *} \\
(0.002)\end{array}$ & $\begin{array}{c}0.106^{* * *} \\
(0.003)\end{array}$ & $\begin{array}{c}0.118^{* * *} \\
(0.003)\end{array}$ & $\begin{array}{c}0.419^{* * *} \\
(0.018)\end{array}$ & $\begin{array}{c}0.525^{* * *} \\
(0.027)\end{array}$ & $\begin{array}{c}0.347^{* * * *} \\
(0.023)\end{array}$ & $\begin{array}{c}0.457^{* * *} \\
(0.017)\end{array}$ & $\begin{array}{c}0.484^{* * *} \\
(0.026)\end{array}$ & $\begin{array}{c}0.436^{* * *} \\
(0.022)\end{array}$ \\
\hline Adjusted R-squared & & & & 0.012 & 0.012 & 0.013 & 0.002 & 0.004 & 0.004 & 0.004 & 0.003 & 0.012 \\
\hline Number of observations & & & & 31750 & 13612 & 18138 & 3573 & 1446 & 2127 & 3573 & 1446 & 2127 \\
\hline
\end{tabular}




\section{Appendix A: Data}

We have collected information from three different sources: (i) information on centralized competitions from the Ministry of Research and Science, (ii) individual research production from ISI Web of Science and (iii) information on doctoral dissertations from TESEO database. Below we describe the process of data collection in detail.

Ministry of Research and Science The system of centralized competitions known as 'habilitación' was in place between 2002 and 2006. Information on candidates' and evaluators' first name, last name and id number was retrieved from the website of the Ministry of Research and Science in July 2009 (http://www.micinn.es). In total, 1016 exams took place, around five per discipline. We restrict the sample in several ways. We exclude exams where the number of available positions was larger or equal than the number of candidates (two exams in Basque Philology and one exam in Textile and Paper Engineering) and disciplines where the number of potential evaluators was not big enough to form a committee (46 exams). ${ }^{19}$ The final database includes 967 exams.

The actual age of individuals is not observable. Instead, we exploit the fact that Spanish ID numbers contain information on their issue date to construct a proxy for the age of native individuals on the basis of his/her national ID number. In Spain police stations are given a range of numbers that they then assign to individuals in a sequential manner. Since it is compulsory for all Spaniards to have an ID number by age 14, two Spaniards with similar ID numbers are likely to be of the same age (and geographical origin). ${ }^{20}$ In order to perform the assignment, we first use registry information on the date of birth and ID numbers of 1.8 million individuals in order to create a correspondence

\footnotetext{
${ }^{19}$ In theses cases, unfilled seats in the committee were filled with professors from related disciplines.

${ }^{20}$ There are a number of exceptions. For instance, this methodology will fail to identify the age of those individuals who obtained their nationality when they were older than 14 . This could be a case of immigrants coming to Spain. Still, immigration was a very rare phenomenon in Spain until the late 1990s. Additionally, some parents may have their kids obtain an ID number before they are 14 . This may be the case particularly after Spain entered in the mid 90s the Schengen zone and IDs became a valid documentation to travel to a number of European countries. Still, individuals born around the introduction of the Schengen zone were generally too young to participate in the public examinations performed during 2002-2006.
} 
table which assigns year of birth to the first four digits of ID number (ranges of 10,000 numbers). To test the precision of this correspondence, we apply it to a publicly available list of 3,000 court secretaries, which contains both the ID number and the date of birth. In $95 \%$ of the cases the assigned age is within a three year-interval of the actual age. In order to minimize potential errors, whenever our age proxy indicated that a candidate to associate professor is less than 27 years old and a candidate to full professor is less than 35 years old, we assign age a missing value (around $5 \%$ of the sample). The choice of these thresholds is justified by survey information, according to which the minimum age at which promotion to associate and full professor positions was granted in Spain before 2002 is respectively 27 and 35 (Cruz-Castro et al. 2006). Our proxy of age is not defined for non-Spaniards (less than 1\% of the sample). We imputed the missing information on age assuming that individuals, for whom the age proxy is missing, have the same age as an average individual of the same academic rank in the same discipline.

The Ministry provides information on affiliation for eligible evaluators. Given that most candidates to full professor positions are themselves eligible evaluators in exams to associate professor positions, it is possible to obtain their affiliation by matching the list of eligible evaluators with the list of candidates. Using this procedure, we were able to obtain the information on affiliation for $93 \%$ of candidates to full professor positions. Information on affiliation at the time of the examination for the remaining $7 \%$ of candidates was obtained from the State Official Bulletin or directly from professors' CVs.

ISI Web of Science Information on scientific publications comes from Thompson ISI Web of Science (WoS). ${ }^{21}$ WoS database includes over 10,000 high-impact journals in Science, Engineering, Medicine and Social Sciences, as well as international proceedings coverage for over 110,000 conferences. Out of these ten thousand journals, approximately two hundred are edited in Spain. For the purpose of this analysis, we considered all articles, reviews, notes and proceedings. We collected information on publications since 1975 by authors based in Spain. As well, we consider citations received by these publications

\footnotetext{
${ }^{21}$ We are grateful to the Fundación Española para la Ciencia y la Tecnología for providing us with access to the data.
} 
before July 2012 .

The assignment of articles to professors is non trivial. For each publication and author, WoS provides information on the surname and on the initial (or, in some cases, initials). Homonymity problems may arise in the case of common surnames (i.e. Garcia, Fernandez, Gonzalez). Moreover, unlike most countries, in Spain individuals typically use two surnames (paternal and maternal) and sometimes also a middle name. A paper authored by a Spanish author may include only the paternal or the maternal surname, or both surnames hyphenated. As well, Spanish authors may sign using their first name, their middle name, or both.

We use the following matching procedure in order to identify authors. First, we match publications with Spanish affiliations to professors using information on surnames and initials. We select the subsample of publications that have a unique match in our list of Spanish professors. This subsample includes 250,000 publications. Second, we use this subsample to create a correspondence table between the 240 scientific areas used by ISI to classify publications and the 190 scientific disciplines used by the Ministry of Education in order to classify professors. Specifically, we assign the ISI area to a given discipline (i) if the proportion of publications in the ISI area by professors from the discipline exceeds $10 \%$ of the total number of publications in the discipline (or viceversa), or (ii) if it appears before the $50 \%$ threshold in the cumulative distribution of publications ordered by the decreasing importance of ISI areas in the discipline (or viceversa). The resulting correspondence table, available upon request, allows matching publications in ISI areas to the scientific areas defined by the Ministry of Education. On average, we assign five ISI areas to each discipline. Finally, using this correspondence table, we merge the ISI publication data with the full list of professors using information on surnames, initials and discipline.

If a given publication can be assigned to more than one possible match, the value of this publication is divided by the number of such possible matches. Less than $3 \%$ of publications were assigned to more than one individual. This figure is equal to $0.5 \%$ in the subsample of individuals with "less common surnames", i.e. individuals whose maternal 
and paternal surnames have a frequency below 100,000 according to the Spanish National Statistical Institute.

Given that propensity to publish differs substantially across disciplines, we normalize the number of individual's publications to have zero mean and unit standard deviation among applicants to the same exam and among eligible evaluators of a given category in a given exam. The number of citations of each publication depends on time elapsed between the publication date and the date when the number of received citations is observed. Therefore, we first normalize the number of citations received by each publication subtracting the average number of citations received by Spanish-authored articles published in the corresponding ISI disciplinary area in the same year and then dividing by the corresponding standard deviation. Next, for each individual in our database we calculate the average number of normalized citations per publication. Finally, similarly to the number of publications, we re-normalize the number of individual's citations per publication to have zero mean and unit standard deviation among applicants to the same exam and among eligible evaluators of a given category in a given exam. We treat individuals who have no ISI publications as if they had received zero citations.

TESEO database on doctoral dissertations Since $1977 \mathrm{PhD}$ candidates in Spanish universities register their dissertation in the database TESEO, which is run by the Ministry of Education. We retrieved all the information available in this database from the website https://www.educacion.gob.es/teseo in May 2011. We observe 151,483 dissertations. TESEO provides the identity and affiliation of dissertations' authors, advisors and committee members.

We are able to find the dissertation of $83 \%$ of candidates to AP exams. Missing information may be due to the fact that (i) individuals did their $\mathrm{PhD}$ abroad, (ii) they defended their dissertation before 1977, (iii) there are spelling mistakes, (iv) there was a homonymity problem ( $0.1 \%$ of individuals share the same name, middle name, paternal surname and maternal surname) or (v) the dissertation was not included in TESEO for unknown reasons. ${ }^{22}$ We use dissertation information to identify candidates' alma mater.

\footnotetext{
${ }^{22}$ While registration is compulsory, according to Fuentes and Arguimbau (2010), TESEO does not
} 
Connections We define different types of connections between candidates and evaluators. First, we consider strong professional connections that imply interaction on a common piece of research, $c_{1}^{\prime}$ : advisor-student relationship and co-authors. These two types of connections are highly intertwined in Spain: around $50 \%$ of individuals have co-authored a paper with their advisor. We use information from ISI on individuals' publication record to identify whether candidates and evaluators have co-authored a paper. In the case when an author of a publication can be assigned to more than one possible match, the co-authorship tie is given a weight equal to the inverse of the number of possible matches. Second, we identify institutional connections, $c_{2}^{\prime}$. In the case of FP exams, we consider that the evaluator and the candidate have an institutional connection if at the time of the examination they are colleagues at the same university. Unfortunately we cannot observe the affiliation of candidates to AP positions at the time of the exam, we only observe the institution where they obtained their $\mathrm{PhD}$. In this case we consider that the evaluator and the candidate have an institutional connection if the candidate obtained her PhD from the university where the evaluator is based. Given the low geographical mobility of Spanish professors at this stage (Cruz-Castro et al. 2006), it seems reasonable to presume that the large majority of candidates to AP positions were still based in their alma mater at the time of the evaluation. Third, we identify the following weak ties between candidates and evaluators, $c_{3}^{\prime}$, which imply some professional interaction: the evaluator was a member of the candidate's thesis committee; the evaluator has invited the candidate to sit on the thesis committee of one of her students (or vice versa); the evaluator and the candidate sat on the same thesis committee. Finally, we identify several indirect ties between candidates and evaluators, $c_{4}^{\prime}$ : the evaluator and the candidate have either a common advisor or a common thesis committee member or a common co-author.

We attribute only one type of connection to a given pair of individuals, following the priority order introduced above. Specifically, given that the co-authorship link is defined include information on approximately $10 \%$ of all dissertations read in Spain. 
probabilistically, we apply the following transformation:

$$
\begin{array}{ll}
c_{1}=c_{1}^{\prime} & c_{3}=\left(1-c_{2}\right) c_{3}^{\prime} \\
c_{2}=\left(1-c_{1}\right) c_{2}^{\prime} & c_{4}=\left(1-c_{3}\right) c_{4}^{\prime}
\end{array}
$$

where $c_{1}, \ldots, c_{4}, c_{1}^{\prime}, \ldots, c_{4}^{\prime} \in[0,1]$.

\section{Appendix B: Expected Committee composition}

In exams to FP positions, the expected number of connections in the committee is essentially equal to the proportion of connections in the pool of eligible FPs times seven (as there are seven evaluators in the committee). However, as explained in footnote 11, the random assignment of evaluators to committees was subject to a constraint: every committee could include at most one researcher from the Spanish Research Council (CSIC) and one emeritus professor. When a second individual belonging to one of these categories was drawn, the draw was not considered. Therefore, in exams where the population of potential evaluators contains two or more researchers, or two or more emeritus professors, the expected number of connections in the committee should be computed taking into account this constraint. This affects 387 of 967 exams.

First, we compute the probability that at least one researcher is drawn from the pool, $p_{R}$, and the probability that at least one emeritus professor is drawn, $p_{E}$. For FP exams these probabilities are:

$$
p_{R}=1-\frac{\left(\begin{array}{c}
R \\
0
\end{array}\right)\left(\begin{array}{c}
P+E \\
7-0
\end{array}\right)}{\left(\begin{array}{c}
P+E+R \\
7
\end{array}\right)}, \quad p_{E}=1-\frac{\left(\begin{array}{c}
E \\
0
\end{array}\right)\left(\begin{array}{c}
P+R \\
7-0
\end{array}\right)}{\left(\begin{array}{c}
P+E+R \\
7
\end{array}\right)}
$$

where $R$ is the number of researchers in the pool, $E$ is the number of emeritus professors and $P$ is the number of eligible professors who are not emeritus. Once these probabilities are computed, it is possible to calculate for each candidate the expected number of 
connections in the committee:

$$
\begin{aligned}
\mu= & p_{R} p_{E}\left(c_{R}+c_{E}+5 c_{P}\right)+p_{E}\left(1-p_{R}\right)\left(c_{E}+6 c_{P}\right) \\
& +p_{R}\left(1-p_{E}\right)\left(c_{R}+6 c_{P}\right)+\left(1-p_{R}\right)\left(1-p_{E}\right) 7 c_{P}
\end{aligned}
$$

where $c_{j}$ indicates the number of connections in group $j$ and $j \in\{R, E, P\}$.

In AP exams, three evaluators are drawn from the pool of eligible FPs, and then four evaluators are drawn from the pool of eligible APs. The expected number of connections in the committee is generally equal to the proportion of connections among FPs times three plus the proportion of connections among APs times four. Again, in order to take into account the constraint on the randomization, analogously to the case of FP exams, we compute the probabilities that at least one researcher and at least one emeritus professor is drawn from each pool: $p_{R}^{F P}, p_{E}^{F P}, p_{R}^{A P}$, and $p_{E}^{A P}$ ). Then we compute the expected number of connections in the committee using the following formula:

$$
\begin{aligned}
\mu= & p_{R}^{F P} p_{E}^{F P}\left(c_{R}^{F P}+c_{E}^{F P}+c_{P}^{F P}\right)+p_{E}^{F P}\left(1-p_{R}^{F P}\right)\left(c_{E}^{F P}+2 c_{P}^{F P}\right) \\
& \left.+p_{R}^{F P}\left(1-p_{E}^{F P}\right)\left(c_{R}^{F P}+2 c_{P}^{F P}\right)+\left(1-p_{R}^{F P}\right)\left(1-p_{E}^{F P}\right) 3 c_{P}^{F P}\right] \\
& +\left[( 1 - p _ { R } ^ { F P } ) ( 1 - p _ { E } ^ { F P } ) \left[p_{R}^{A P} p_{E}^{A P}\left(c_{R}^{A P}+c_{E}^{A P}+2 c_{P}^{A P}\right)+p_{E}^{A P}\left(1-p_{R}^{A P}\right)\left(c_{E}^{A P}+3 c_{P}^{A P}\right)\right.\right. \\
& \left.+p_{R}^{A P}\left(1-p_{E}^{A P}\right)\left(c_{R}^{A P}+3 c_{P}^{A P}\right)+\left(1-p_{R}^{A P}\right)\left(1-p_{E}^{A P}\right) 4 c_{P}^{A P}\right] \\
& +p_{R}^{F P}\left(1-p_{E}^{F P}\right)\left[p_{E}^{A P}\left(c_{E}^{A P}+3 c_{P}^{A P}\right)+\left(1-p_{E}^{A P}\right) 4 c_{P}^{A P}\right] \\
& \left.+p_{E}^{F P}\left(1-p_{R}^{F P}\right)\left[p_{R}^{A P}\left(c_{R}^{A P}+3 c_{P}^{A P}\right)+\left(1-p_{R}^{A P}\right) 4 c_{P}^{A P}\right]+p_{E}^{F P} p_{R}^{F P} 4 c_{P}^{A P}\right]
\end{aligned}
$$

where $c_{j}^{k}$ is the proportion of connections in the pool of $k \in\{F P, A P\}$ professors belonging to group $j \in\{R, E, P\}$. 